\title{
Editorial
}

\section{Polidocanol Foam: A Breath of Fresh Air for the Treatment of Internal Hemorrhoids}

\author{
Bruno Rosa \\ Gastroenterology Department, Hospital da Senhora da Oliveira, Guimarães, Portugal
}

\section{Keywords}

Hemorrhoids treatment $\cdot$ Sclerotherapy $\cdot$ Polidocanol foam

\section{Polidocanol espumoso: uma lufada de ar fresco no tratamento das hemorroidas internas}

\section{Palavras Chave}

Tratamento de hemorroidas · Escleroterapia •

Polidocanol espumoso

Hemorrhoidal disease is commonly diagnosed in clinical practice, ranging from $4 \%$ in self-reporting surveys [1] to almost $40 \%$ in screening colonoscopy studies [2]. Due to the intermittent nature of clinical symptoms, feelings of embarrassment or fear of examinations, patients often rely on coping strategies or opt for self-medication many years before getting medical care. Conservative treatment is successful for most patients with symptomatic grade I or II internal hemorrhoids, including dietary and lifestyle modification to reduce constipation and straining at defecation, as well as topical or oral medications to relieve symptoms [3], although there are few data

\section{KARGER}

E-Mail karger@karger.com www.karger.com/pjg
(C) 2018 Sociedade Portuguesa de Gastrenterologia Published by S. Karger AG, Basel

Karger

Open access

This article is licensed under the Creative Commons AttributionNonCommercial-NoDerivatives 4.0 International License (CC BYNC-ND) (http://www.karger.com/Services/OpenAccessLicense). Usage and distribution for commercial purposes as well as any distribution of modified material requires written permission. on the long-term efficacy or side effects of most of these agents.

For patients with symptomatic internal hemorrhoids refractory to conservative treatment, an office-based procedure such as rubber band ligation, sclerotherapy, or infrared coagulation, rather than surgical hemorrhoidectomy, should be recommended as the initial intervention. Surgical treatment is associated with more pain and more complications such as bleeding, anal deformity, and incontinence, being usually reserved for patients with permanently prolapsed grade IV hemorrhoids, concurrent symptomatic external hemorrhoids, or failure of nonsurgical treatment [4]. Although the preferred technique may depend on diverse factors such as local availability and expertise, rubber band ligation has often been recommended as the first choice for healthy patients especially with grade II or III internal hemorrhoids, generally providing a higher efficacy with fewer treatment sessions and fewer recurrences, although at the cost of a higher risk of complications such as pain and delayed bleeding when compared with sclerotherapy or infrared coagulation [5, 6]. One of the largest series evaluating the long-term outcomes of rubber band ligation achieved a success rate of $71 \%$ with a single procedure, reaching $80 \%$ when considering repeated treatment after initial failure [7]. 
The injection of a sclerosing agent such as polidocanol, usually $2 \mathrm{ml}$ in its conventional liquid form, has been widely regarded as a less effective technique, often reserved for smaller or less prolapsed hemorrhoids, although it may be particularly beneficial in immunocompromised patients or those on anticoagulant or antiplatelet drugs, with lower risk of delayed bleeding and anorectal sepsis when compared with rubber band ligation or hemorrhoidectomy [8]. The study by Fernandes et al. [9] addresses a significantly large population of 2,000 patients, reflecting the experience and expertise of the authors with a modified sclerotherapy technique based on polidocanol foam, obtained by simply adding air to the classical liquid form on a syringe; although quite familiar among vascular surgeons, to date this mixture has been seldomly used by gastroenterologists to treat symptomatic internal hemorrhoids. A higher volume of the foamy polidocanol can be injected, and it may provide better adhesion to the endothelium and increased sclerosing capacity, with improved efficacy ( $98 \%$ of patients reporting bleeding cessation and $86 \%$ with objective reduction of prolapse), tolerability (92\% reporting no or only mild pain), and equivalent safety ( $0.7 \%$ complications), even in patients with larger and significantly prolapsed hemorrhoids (grade II: 61\%, grade III: 29\%, grade IV: $10 \%$ ), after a single or two sessions in the vast majority of cases. Although limited by the lack of a control group and the technique being executed by a single operator, the results were impressive, prompting the authors to suggest the use of polidocanol foam as the first-line treatment for most patients with symptomatic internal hemorrhoids, including those under anticoagulation and antiplatelet therapy. While further validation is expected, we may well be on the verge of a paradigm shift for the officebased treatment of hemorrhoidal disease - more than just filling in the hemorrhoidal cushions, the polidocanol foam may contribute to fulfill our ambition as physicians to always get the best results for our patients through safer, less invasive, and well-tolerated treatments.

\section{Disclosure Statement}

The author has no conflicts of interest to declare.

\section{References}

1 Johanson JF, Sonnenberg A: The prevalence of hemorrhoids and chronic constipation. An epidemiologic study. Gastroenterology 1990; 98:380-386

2 Riss S, Weiser FA, Schwameis K, Riss T, Mittlbock M, Steiner G, Stift A: The prevalence of hemorrhoids in adults. Int J Colorectal Dis 2012;27:215-220.

3 Perera N, Liolitsa D, Iype S, Croxford A, Yassin M, Lang P, Ukaegbu O, van Issum C: Phlebotonics for haemorrhoids. Cochrane Database Syst Rev 2012(8):CD004322.
4 Shanmugam V, Thaha MA, Rabindranath KS, Campbell KL, Steele RJ, Loudon MA: Rubber band ligation versus excisional haemorrhoidectomy for haemorrhoids. Cochrane Database Syst Rev 2005(3):CD005034.

5 MacRae HM, McLeod RS: Comparison of hemorrhoidal treatments: a meta-analysis. Can J Surg 1997;40:14-17.

6 Poen AC, Felt-Bersma RJ, Cuesta MA, Deville W, Meuwissen SG: A randomized controlled trial of rubber band ligation versus infra-red coagulation in the treatment of internal haemorrhoids. Eur J Gastroenterol Hepatol 2000;12:535-539.
7 Iyer VS, Shrier I, Gordon PH: Long-term outcome of rubber band ligation for symptomatic primary and recurrent internal hemorrhoids. Dis Colon Rectum 2004;47:13641370.

8 Scaglia M, Delaini GG, Destefano I, Hulten L: Injection treatment of hemorrhoids in patients with acquired immunodeficiency syndrome. Dis Colon Rectum 2001;44:401-404.

9 Fernandes V, Fonseca J: Polidocanol foam injected at high doses with intravenous needle: the (almost) perfect treatment of symptomatic internal hemorrhoids. GE Port J Gastroenterol DOI: 10.1159/000492202. 